\title{
Lycopene Protects Against Spontaneous Ovarian Cancer Formation in Laying Hens
}

\section{Kazim Sahin ${ }^{1}$, Engin Yenice ${ }^{2}$, Mehmet Tuzcu ${ }^{3}$, Cemal Orhann ${ }^{1}$, Cengizhan Mizrak², Ibrahim H. Ozercan ${ }^{4}$, Nurhan Sahin ${ }^{1}$, Bahiddin Yilmaz ${ }^{5}$, Birdal Bilir ${ }^{5}$, Bulent Ozpolat ${ }^{6}$, Omer Kucuk ${ }^{5}$}

'Department of Animal Nutrition, Faculty of Veterinary Science, Firat University, Elazig, ${ }^{2}$ Poultry Research Institute, Ankara, ${ }^{3}$ Division of Biology, Faculty of Science, Firat University, ${ }^{4}$ Department of Pathology, Faculty of Medicine, Firat University, Elazig, Turkey, ${ }^{5}$ Winship Cancer Institute of Emory University, Atlanta, GA, ${ }^{6}$ Department of Experimental Therapeutics, University of Texas MD Anderson Cancer Center, Houston, TX, USA

\begin{abstract}
Background: Dietary intake of lycopene has been associated with a reduced risk of ovarian cancer, suggesting its chemopreventive potential against ovarian carcinogenesis. Lycopene's molecular mechanisms of action in ovarian cancer have not been fully understood. Therefore, in the present study, we investigated the effects of lycopene on the ovarian cancer formation using the laying hen model, a biologically relevant animal model of spontaneous ovarian carcinogenesis due to high incidence rates similar to humans.

Methods: In this study, a total of 150 laying hens at age of 102 weeks were randomized into groups of 50: a control group (0 mg of lycopene per $\mathrm{kg}$ of diet) and two treatment groups (200 mg or $400 \mathrm{mg}$ of lycopene per $\mathrm{kg}$ of diet, or $\sim 26$ and $52 \mathrm{mg} / \mathrm{d} / \mathrm{hen}$, respectively). At the end of 12 months, blood, ovarian tissues and tumors were collected.

Results: We observed that lycopene supplementation significantly reduced the overall ovarian tumor incidence $(P<0.01)$ as well as the number and the size of the tumors $(P<0.004$ and $P<0.005$, respectively). Lycopene also significantly decreased the rate of adenocarcinoma, including serous and mucinous subtypes $(P<0.006)$. Moreover, we also found that the serum level of oxidative stress marker malondialdehyde was significantly lower in lycopene-fed hens compared to control birds $(P<0.001)$. Molecular analysis of the ovarian tumors revealed that lycopene reduced the expression of NF-KB while increasing the expression of nuclear factor erythroid 2 and its major target protein, heme oxygenase 1. In addition, lycopene supplementation decreased the expression of STAT3 by inducing the protein inhibitor of activated STAT3 expression in the ovarian tissues.

Conclusions: Taken together, our findings strongly support the potential of lycopene in the chemoprevention of ovarian cancer through antioxidant and anti-inflammatory mechanisms.
\end{abstract}

(J Cancer Prev 2018;23:25-36)

Key Words: Lycopene, Ovarian cancer, Laying hen model, Chemoprevention, Transcription factors

\section{INTRODUCTION}

According to GLOBOCAN estimates of cancer incidence and mortality for 2012 in 184 countries worldwide, ovarian cancer is the seventh most common malignancy $(239,000$ cases) and the eighth leading cause of cancer mortality (152,000 deaths) in women. ${ }^{1}$ In the United States, 22,440 new cases of ovarian cancer and 14,080 ovarian cancer deaths were estimated in $2017 .{ }^{2}$ Risk factors for ovarian cancer include age, family history, hormone replacement therapy, obesity, nulliparity, and smoking. ${ }^{3}$ In contrast, factors associated with the decreased lifetime number of ovulatory cycles, such as pregnancy, breast feeding, use of oral contraceptives, fallopian tube ligation, and hysterectomy, have been reported to reduce ovarian cancer risk. ${ }^{3}$ Ovarian cancer has been associated with poor prognosis and the highest mortality rate of all gynecological malignancies due to the presence of

Received January 30, 2018, Revised March 9, 2018, Accepted March 9, 2018

Correspondence to: Omer Kucuk

Winship Cancer Institute of Emory University, 1365 Clifton Road NE, Room C-4094, Atlanta, GA 30322, USA

Tel: +1-404-778-3460, Fax: +1-404-778-5520, E-mail: okucuk@emory.edu, ORCID: Omer Kucuk, http://orcid.org/0000-0002-4755-0507

Copyright (c) 2018 Korean Society of Cancer Prevention

(c) This is an Open Access article distributed under the terms of the Creative Commons Attribution Non-Commercial License (http://creativecommons.org/licenses/by-nc/4.0) which permits unrestricted non-commercial use, distribution, and reproduction in any medium, provided the original work is properly cited. 
advanced stages of disease at the time of diagnosis. About $70 \%$ of the patients are diagnosed with distant-stage disease, for which 5 -year survival rate is $25 \%$ to $30 \%$ whereas the survival rate is more than $90 \%$ for patients diagnosed with localized disease. ${ }^{4.5}$ The lack of specific symptoms and reliable molecular biomarkers makes early detection of ovarian cancer challenging. ${ }^{6-8}$ Furthermore, due to the heterogeneous nature of the tumors and resistance to conventional chemotherapeutic drugs, the efficacy of current treatments for ovarian cancer has been limited. Therefore, there is an urgent need for the development of novel and effective approaches to reduce the incidence and mortality of the disease. It is of particular interest to note that chemoprevention provides a promising strategy for ovarian cancer risk reduction.

Epidemiological studies have documented that there is a wide variability in the incidence of ovarian cancer among different countries, with the highest rates in Western countries and the lowest rates in Asian and African countries, suggesting that dietary factors and lifestyle may play a key role in the etiology of the disease. ${ }^{9110}$ Increasing evidence has demonstrated that high dietary intake of lycopene, one of the bioactive components in a variety of foods, is associated with reduced risk of ovarian cancer, supporting the protective role of lycopene against ovarian cancer. ${ }^{11-16}$ Lycopene, which is a lipophilic red pigment, is the most abundant carotenoid in tomatoes and is also found, to a lesser extent, in watermelons, pink grapefruits, carrots, apricots, and guavas. ${ }^{17}$ Lycopene is an acyclic isomer of $\beta$-carotene and it lacks vitamin A activity. ${ }^{18}$ Due to its highly unsaturated hydrocarbon chain with 11 conjugated and two unconjugated double bonds, lycopene exerts effective singlet oxygen quenching and peroxyl radical scavenging activities, resulting in strong antioxidant capacity. ${ }^{19}$ Although the chemopreventive effects of lycopene have been primarily attributed to its antioxidant properties, other potential mechanisms of action have also been reported in cancer prevention. In vitro and in vivo studies have shown that lycopene modulates various cellular processes, including growth factor signaling pathways (insulin-like growth factor, platelet-derived growth factor, and vascular endothelial growth factor [VEGF]), ${ }^{20-22}$ cell cycle, ${ }^{23,24}$ apoptosis, ${ }^{25,26}$ and metastasis, ${ }^{27,28}$ by acting on molecular targets, such as phosphoinositide 3-kinase, AKT, mitogen-activated protein kinases, NF- $\kappa$ B, activating protein-1 [AP-1], TNF- $\alpha$, COX-2, interleukin-6, matrix metalloproteinases, and $\beta$-catenin. Moreover, lycopene has been reported to counteract the suppression of gap junctional communication during carcinogenesis, leading to inhibition of cell growth. ${ }^{29}$ Efficacy studies have demonstrated that lycopene in combination with other natural anticancer compounds has synergistic inhibitory effects on tumor growth. ${ }^{30-33}$ In addition, lycopene has been shown to act as a chemosensitizer ${ }^{34.36}$ and a radiosensitizer $^{37,38}$ for cancer cells, and ameliorate the adverse side effects of the anticancer therapies. ${ }^{35,37}$

Although epidemiological studies have shown the inverse association between dietary lycopene intake and ovarian cancer risk, the molecular mechanisms underlying the preventive effects of lycopene on ovarian carcinogenesis have not been fully elucidated. Among the animal models of ovarian cancer, the laying hen (Gallus domesticus) has great potential to provide the most relevant preclinical model that recapitulates the etiology and progression of the disease in human. The fact that laying hen is the only non-human animal that spontaneously develops ovarian cancer at a high incidence makes the laying hen model unique among animal models to study the ovarian tumorigenesis. ${ }^{39}$ Importantly, similar to humans, laying hens have been shown to have high ovulatory rates, suggesting the possibility of a similar pathogenesis associated with ovulation-induced inflammatory event, resulting in DNA damage to ovarian epithelial cells in both hen and human ovarian cancers. ${ }^{40}$ As in women, use of oral contraceptives to inhibit ovulation in the laying hens has been reported to be associated with a risk reduction of ovarian cancer. ${ }^{41}$ In addition, ovarian tumor cells in laying hens exhibit molecular characteristics similar to those of human ovarian cancer cells, including the expression of several biomarkers (cytokeratin, cancer antigen 125 [CA125], VEGF, epidermal growth factor receptor [EGFR], human epidermal growth factor receptor 2, CYP1B1, and proliferating cell nuclear antigen [PCNA]). ${ }^{42-45}$ Interestingly, the histopathological subtypes of ovarian tumors in humans (serous, endometrioid, mucinous, and clear cell carcinomas) are also observed in hens. ${ }^{46}$ Therefore, in the present study, we utilized the laying hen model to investigate the effects of lycopene on the development of spontaneous ovarian cancer, providing mechanistic insights into the mode of action of lycopene in the prevention of ovarian cancer.

\section{MATERIALS AND METHODS}

\section{Animal husbandry and experimental design}

A total of 150 brown laying hens (ATAK-S hybrid, Gallus domesticus) at 102 weeks of age were maintained in accordance with the animal welfare regulations at the Ankara Poultry Research Station, Turkey. Hens were housed five per cage under a 14-hour light and 10-hour dark cycle with access to water and diet ad libitum. Animals were assigned randomly to three groups with 
50 hens in each group: a control group ( $0 \mathrm{mg}$ of lycopene per $\mathrm{kg}$ of diet) and two treatment groups (200 mg or $400 \mathrm{mg}$ of lycopene per $\mathrm{kg}$ of diet, equivalent of approximately 26 and $52 \mathrm{mg} / \mathrm{d} / \mathrm{hen}$, respectively). Ingredients and composition of basal diet are shown in Table 1. Experimental diets were prepared by supplementing the basal diet with water-soluble lycopene (Redivivo, CWS/S-TG), which was supplied by DSM (Istanbul, Turkey). Diets were stored in black plastic containers at $4^{\circ} \mathrm{C}$ to avoid photooxidation.

\section{Necropsy and tissue collection}

At the end of lycopene administration for 12 months, blood samples were collected from the axillary vein, and animals were euthanized, followed by necropsy. Hens were evaluated for abnormal ovarian morphology (tumors, cysts, and solid mass) by gross examination. Tumor incidence and the number and size of tumors were recorded.

\section{Histological analysis}

Upon necropsy, ovarian tissues were removed and placed in

Table 1. Composition of the basal diet

\begin{tabular}{lc}
\hline \multicolumn{1}{c}{ Variable } & Value \\
\hline Ingredient $(\mathrm{g} / \mathrm{kg})$ & \\
Corn & 630.0 \\
Soybean meal & 195.8 \\
Meat-bone meal & 50.0 \\
Soy oil & 22.7 \\
Limestone & 89.0 \\
Dicalcium phosphate & 2.5 \\
Mineral premix ${ }^{\mathrm{a}}$ & 3.0 \\
Vitamin premix & \\
Sodium chloride & 3.0 \\
Sodium bicarbonate & 2.0 \\
Chemical analyses, dry matter basis $(\%)$ & 2.0 \\
Crude protein & \\
Crude fat & 17.02 \\
Crude fiber & 4.50 \\
Crude ash & 3.52 \\
Calcium & 12.08 \\
Phosphorus & 4.0 \\
Calculated compositions & 0.35 \\
Methionine & \\
Lysine & 0.46 \\
Metabolizable energy (kcal/kg) & 0.91 \\
\end{tabular}

${ }^{\mathrm{a}}$ Supplied per kilogram of diet: retinyl acetate, 12,000 IU; cholecalciferol, 2,400 IU; dl- $\alpha$-tocopheryl acetate, $30 \mathrm{mg}$; menadione sodium bisulfite, $2,5 \mathrm{mg}$; thiamine-hydrochloride, $3 \mathrm{mg}$; riboflavin, $7 \mathrm{mg}$; niacin, $40 \mathrm{mg}$; d-pantothenic acid, $8 \mathrm{mg}$; pyridoxine hydrochloride, $4 \mathrm{mg}$; vitamin $\mathrm{B}_{12}, 0,015 \mathrm{mg}$; vitamin C, $50 \mathrm{mg}$; folic acid, $1 \mathrm{mg}$; D-biotin, 0,045 mg; choline chloride, $125 \mathrm{mg}$; $\mathrm{Mn}\left(\mathrm{MnSO}_{4}-\mathrm{H}_{2} \mathrm{O}\right)$, $80 \mathrm{mg} ; \mathrm{Fe}\left(\mathrm{FeSO}_{4}-7 \mathrm{H}_{2} \mathrm{O}\right), 30 \mathrm{mg} ; \mathrm{Zn}(\mathrm{ZnO}), 60 \mathrm{mg} ; \mathrm{Cu}\left(\mathrm{CuSO}_{4}-5 \mathrm{H}_{2} \mathrm{O}\right)$, $5 \mathrm{mg}$; $\mathrm{Co}\left(\mathrm{CoCl}_{2}-6 \mathrm{H}_{2} \mathrm{O}\right), 0,1 \mathrm{mg}$; I as $\mathrm{KI}, 0,4 \mathrm{mg}$; $\mathrm{Se}\left(\mathrm{Na}_{2} \mathrm{SeO}_{3}\right), 0,15 \mathrm{mg}$.
$10 \%$ neutral-buffered formalin. After fixation in formalin, tissues were processed by paraffin embedding, sectioned at $6 \mu \mathrm{m}$, stained with hematoxylin and eosin, and examined under light microscope. Histological types were classified as normal, tumor, adenocarcinoma, or lesions.

\section{Analysis of serum levels of malondialdehyde and lycopene}

Serum was separated by centrifuging the blood sample at $3,000 \times g$ for 10 minutes and analyzed for malondialdehyde (MDA) and lycopene levels by high-performance liquid chromatography (HPLC) using a Shimadzu HPLC system with an SPD-10A VP UV-Vis detector and an ODS C18 column $(250 \times 4.6 \mathrm{~mm}$ internal diameter and $5 \mu \mathrm{m}$ particle size) (Shimadzu, Tokyo, Japan) as described previously. ${ }^{47}$

To quantify MDA concentration, $300 \mu \mathrm{L}$ of serum sample was homogenized in a mixture of $200 \mu \mathrm{L}_{\text {of }} \mathrm{HClO}_{4}(0.5 \mathrm{M})$ and $100 \mu \mathrm{L}$ of $500 \mathrm{ppm}$ butylated hydoxytoluene (BHT), and centrifuged. An aliquot of $20 \mu \mathrm{L}$ of supernatant was injected into an HPLC column. Samples were eluted with a mobile phase containing $30 \mathrm{mM}$ of $\mathrm{KH}_{2} \mathrm{PO}_{4}$-methanol (82.5: 17.5, v/v, pH 3.6) at a flow rate of $1.2 \mathrm{~mL} /$ minute. Chromatograms were acquired at $250 \mathrm{~nm}$.

To measure the lycopene concentration, serum sample was mixed with a KOH/ethanol solution (1 : 5) containing 0.1\% BHT, followed by addition of deionized water. Serum lycopene was extracted three times with addition of hexane. Hexane extracts were dried under nitrogen in dark and subsequently dissolved in $100 \mu \mathrm{L}$ of mobile phase. All extracts were kept on ice and protected from light. HPLC analysis was performed on a column with methanol : acetonitrile : dichloromethane : water $(7: 7: 20$ : 0.16 ) containing $20 \mathrm{mmol} / \mathrm{L}$ ammonium acetate at flow rate of 1 $\mathrm{mL} / \mathrm{min}$ and detection was performed at $470 \mathrm{~nm}$.

\section{Western blot analysis}

Protein lysates from ovarian tissues (normal or tumor tissues) were prepared as described previously. ${ }^{48}$ Briefly, ovarian tissues were homogenized in lysis buffer (10 mM Tris-HCl [pH 7.4], 0.1 $\mathrm{mM} \mathrm{NaCl}, 0.1 \mathrm{mM}$ phenylmethylsulfonyl fluoride and $5 \mu \mathrm{M}$ soluble soybean powder [Sigma, St. Louis, MO, USA] as trypsin inhibitor) at $1: 10(\mathrm{w} / \mathrm{v})$, and centrifuged at $15,000 \times g$ at $4^{\circ} \mathrm{C}$ for 30 minutes. Supernatant was collected and protein concentration was determined. Protein sample was mixed with Laemmli sample buffer containing $\beta$-mercaptoethanol, and incubated at $95^{\circ} \mathrm{C}$ for 5 minutes. Twenty $\mu \mathrm{g}$ of total protein was separated on $10 \%$ SDS PAFE and transferred onto nitrocellulose membrane (Schleicher and Schuell Inc., Keene, NH, USA). Membranes were 
washed twice for 5 minutes with PBS and incubated in blocking solution (PBS containing 1\% bovine serum albumin) for 1 hour. Blots were then incubated overnight at $4^{\circ} \mathrm{C}$ with primary antibodies against NF- $\kappa$ B, STAT3, nuclear factor erythroid 2 (NFE2)-related factor 2 (Nrf2), protein inhibitor of activated STAT 3 (PIAS3), and heme oxygenase 1 (HO-1) (Abcam, Cambridge, UK) diluted at $1:$ 1,000 in the PBS buffer containing 0.05\% Tween 20. Blots were washed and incubated with horseradish peroxidaseconjugated goat anti-mouse immunoglobulin G (Abcam). Detection was performed using diaminobenzidine and hydrogen peroxide as substrates. $\beta$-actin antibody (Sigma) was used as normalization control. Quadruplicates were run for each sample. Protein intensities were quantitated densitometrically using ImageJ analysis system (National Institute of Health, Bethesda, MD, USA).

\section{Statistical analysis}

Differences in the tumor incidences and numbers in the groups were evaluated statistically using the chi-square $\chi^{2}$ test. Data were analyzed via analysis of variance using the general linear model with the SAS program (2002) (SAS Institute, Cary, $\mathrm{NC}$, USA) to determine the effects of lycopene supplementation on tumor diameter, protein staining intensities, and serum metabolites. When a significant $\mathrm{F}$ statistic $(P \leq 0.05)$ in the ANOVA was noted, the mean procedure was performed to separate means that were significantly different $(P<0.05)$.

\section{RESULTS}

\section{Lycopene reduces the incidence and the size of spontaneous ovarian tumors in laying hens}

In this pilot study, we conducted a three-armed controlled trial to prospectively test the effects of lycopene intervention on the development of spontaneous ovarian cancer in the laying hen model. A total of 150 laying hens at 102 weeks of age were randomly assigned into groups of 50: a control group (0 mg of lycopene per $\mathrm{kg}$ of diet) and two treatment groups (200 mg or 400 $\mathrm{mg}$ of lycopene per $\mathrm{kg}$ of diet). At the end of 12-month period of lycopene administration, the necropsy examination of the hens indicated a preventive effect of lycopene on the incidence of spontaneous ovarian cancer (Table 2). Our finding that $40 \%$ of the hens (20/50) fed the control diet developed ovarian cancer spontaneously was consistent with previously published data. ${ }^{49}$ As shown in Table 2, lycopene supplementation significantly decreased the tumor incidence in the ovary of laying hens in comparison with control animals $(P<0.010)$. Gross pathology results showed that 34\% (of the hens 17/50) in $200 \mathrm{mg} / \mathrm{kg}$ group had ovarian tumors whereas only $14 \%$ of the (7/50) animals in $400 \mathrm{mg} / \mathrm{kg}$ group developed ovarian cancer, indicating that lycopene acts in a dose-dependent manner in ovarian cells. Moreover, lycopene treatment significantly reduced both the number and size of ovarian tumors compared to the control group (Table 2). While $8 \%$ of the control animals had multiple ovarian tumors, none of the hens in the treatment groups developed multiple tumors. Hens in the control group had an average of 0.48

Table 2. Effects of lycopene on ovarian cancer prevention in laying hens

\begin{tabular}{|c|c|c|c|c|}
\hline \multirow{2}{*}{ Item } & \multicolumn{3}{|c|}{ Lycopene dose $(\mathrm{mg} / \mathrm{kg}$ of diet $)$} & \multirow{2}{*}{$P$-value } \\
\hline & 0 & 200 & 400 & \\
\hline Tumor incidence $(\mathrm{n})$ & $20 / 50(40.0)^{\mathrm{a}}$ & $17 / 50(34.0)^{\mathrm{a}}$ & $7 / 50(14.0)^{\mathrm{b}}$ & $<0.010\left(\chi^{2}=8.94\right)$ \\
\hline 0 & $30 / 50(60.0)$ & $33 / 50(66.0)$ & $43 / 50(86.0)$ & \\
\hline 1 & $16 / 50$ & $17 / 50(34.0)$ & $7 / 50(14.0)$ & \\
\hline$>1$ & $4 / 50(8.0)$ & $0 / 50(0)$ & $0 / 50(0)$ & \\
\hline Number of tumor & $0.48 \pm 0.09^{\mathrm{a}}$ & $0.34 \pm 0.07^{\mathrm{ab}}$ & $0.14 \pm 0.05^{\mathrm{b}}$ & $<0.004$ \\
\hline Size $(\mathrm{mm})$ & $6.64 \pm 1.51^{\mathrm{a}}$ & $3.98 \pm 0.93^{\mathrm{ab}}$ & $1.56 \pm 0.59^{\mathrm{b}}$ & $<0.005$ \\
\hline Serous carcinoma & & & & $<0.03\left(\chi^{2}=7.00\right)$ \\
\hline Number of incidence & $14 / 50^{\mathrm{a}}$ & $12 / 50^{\mathrm{a}}$ & $4 / 50^{b}$ & \\
\hline$\%$ of incidence & 28 & 24 & 8 & \\
\hline$\%$ of reduction in incidence & - & 14 & 71 & \\
\hline Mucinous carcinoma & & & & $<0.576\left(\chi^{2}=1.10\right)$ \\
\hline Number of incidence & $6 / 50$ & $5 / 50$ & $3 / 50$ & \\
\hline$\%$ of incidence & 12 & 10 & 6 & \\
\hline$\%$ of reduction in incidence & - & 17 & 50 & \\
\hline
\end{tabular}

Values are presented as number/total number (persentage), mean $\pm \mathrm{SE}$, or persentage only from a 450-day animal experimentation. ${ }^{\text {a.b }}$ Percent or means in the same line without a common superscript differ significantly $(P<0.05)$. 
tumors whereas the animals fed $200 \mathrm{mg} / \mathrm{kg}$ and $400 \mathrm{mg} / \mathrm{kg}$ of lycopene had 0.34 and 0.14 tumors, respectively $(P<0.004)$. We observed that the mean tumor size was $6.64 \mathrm{~mm}$ in the control group while it was $3.98 \mathrm{~mm}$ and $1.56 \mathrm{~mm}$ in $200 \mathrm{mg} / \mathrm{kg}$ and $400 \mathrm{mg} / \mathrm{kg}$ groups, respectively $(P<0.005)$, indicating a significant inhibition of tumor growth and further supporting the preventive role of lycopene in ovarian cancer.

\section{Lycopene reduces adenocarcinoma of the ovary in laying hen}

At the time of necropsy, animals were examined extensively for the presence of ovarian abnormalities. Gross examination demonstrated that hens with normal ovaries had a higher number of developing follicles compared to those with ovarian abnormalities. Non-tumor ovarian abnormalities in hens were characterized by the presence of atretic follicles with fat globules in the degenerating granulosa and theca cells as well as cysts. Macroscopic assessment also showed that ovarian abnormalities in laying hens were associated with atresia of 2-3 large preovulatory hierarchical follicles and the presence of multiple cysts. In hens with cancerous ovary, the tumors had solid nodular masses and no large yolky preovulatory follicles were observed in the ovary (Fig. 1). In some hens, tumors were metastasized to peritoneal organs with profuse ascites. Representative images of histologic analysis of ovarian tissues from normal and carcinoma cases are shown in Figure 2. Features of endometrioid type carcinoma were observed in some hens as glandular structures lined by columnar, cuboidal, or oval epithelial cells. Poorly differentiated or mixed ovarian carcinomas were also identified in some cases.

Histopathological analysis of ovarian tissues demonstrated a significant difference in the rate of spontaneous adenocarcinoma between control and treatment groups (Table 2). While adenocarcinoma was observed in 20/50 of the hens (40\%) in the control group, the animals fed lycopene developed significantly less adenocarcinoma with 17/50 (34\%) and 7/50 (14\%) in $200 \mathrm{mg} / \mathrm{kg}$
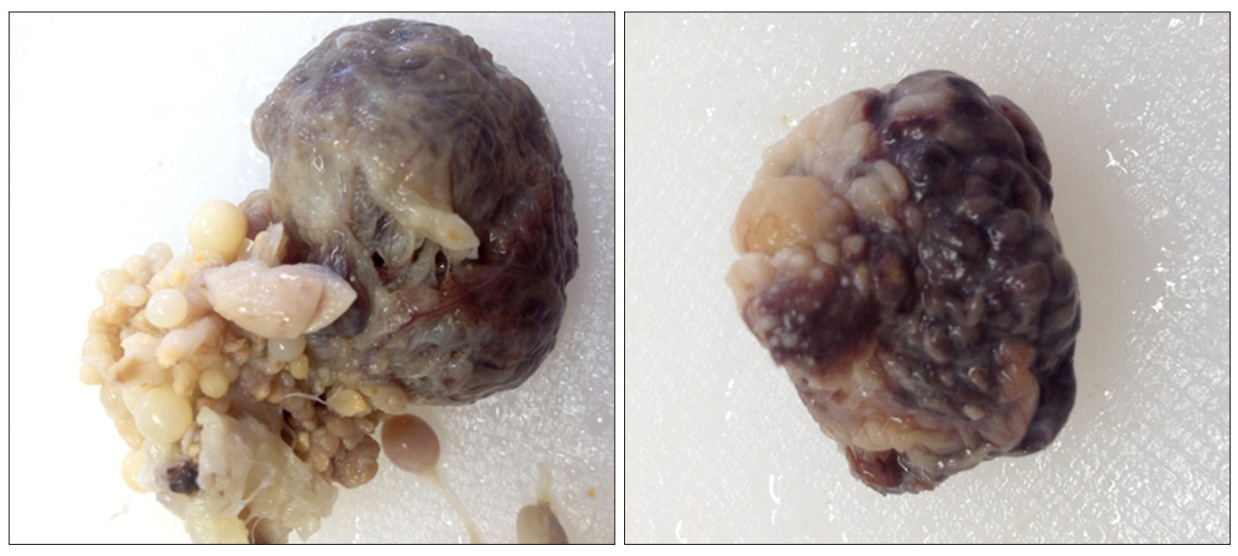

Figure 1. Gross morphology of ovaries in egg-laying hens with primary malignant ovarian tumors. The tumors are limited to the ovary. Multiple solid tumors are observed.
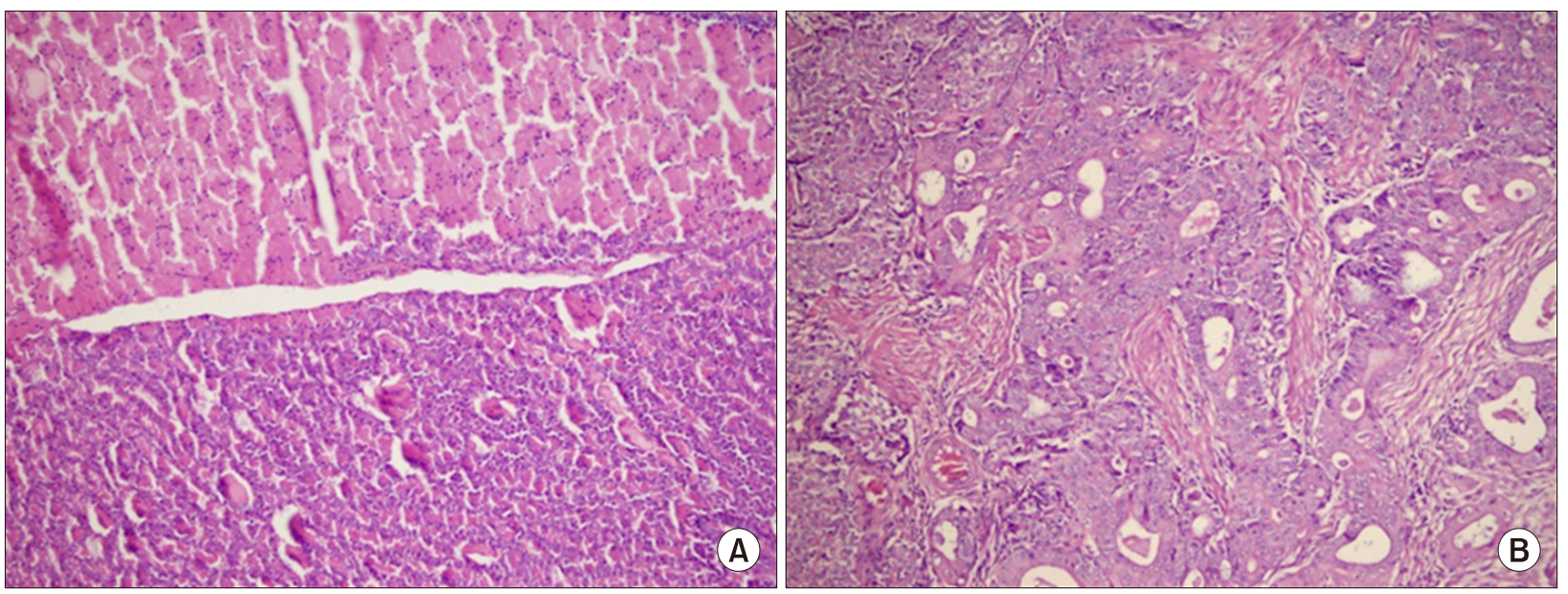

Figure 2. Hematoxylin and eosin staining of (A) normal ovarian tissue and (B) ovarian adenocarcinoma in egg-laying hens. Original magnification is $\times 40$. 
and $400 \mathrm{mg} / \mathrm{kg}$ groups, respectively $(P<0.03)$. In the control group, $14 / 50$ of the animals (28\%) had serous carcinomas and 6/50 (12\%) had mucinous carcinomas. In $200 \mathrm{mg} / \mathrm{kg}$ lycopene group, there were $12 / 50$ birds (24\%) with serous and 5/50 (10\%) mucinous carcinomas, and in $400 \mathrm{mg} / \mathrm{kg}$ lycopene group, there were 4/50 birds (8\%) with serous and 3/50 (6\%) mucinous carcinomas.

\section{Lycopene decreases serum levels of an oxidative stress marker in laying hens}

As shown in Table 3, no lycopene was detected in the serum samples of hens from control group. However, hens fed lycopene had significantly elevated serum lycopene levels in comparison with the control animals $(P<0.001)$. Additionally, the increase in the level of serum lycopene was shown to be dose-dependent $(6.29 \mathrm{nmol} / \mathrm{mL}$ and $13.75 \mathrm{nmol} / \mathrm{mL}$ in $200 \mathrm{mg} / \mathrm{kg}$ and $400 \mathrm{mg} / \mathrm{kg}$ groups, respectively). To explore the effects of lycopene supplementation on oxidative stress in the laying hen model, we analyzed the levels of serum MDA, a well-documented biomarker of oxidative stress, using HPLC (Table 3). Our data showed that hens fed lycopene exhibited the significantly decreased serum MDA levels in comparison with the control hens, and the reduction was in a dose-dependent manner $(P<0.001)$. Mean serum MDA level was determined as $2.26 \mathrm{nmol} / \mathrm{mL}$ in the control group while it was found to be $1.65 \mathrm{nmol} / \mathrm{mL}$ and $0.90 \mathrm{nmol} / \mathrm{mL}$ in $200 \mathrm{mg} / \mathrm{kg}$ and $400 \mathrm{mg} / \mathrm{kg}$ groups, respectively. These results demonstrate an inverse correlation between levels of lycopene and oxidative stress, supporting the hypothesis that lycopene supplementation could ameliorate oxidative stress in the hen ovary.

\section{Lycopene suppresses the NF- $\mathrm{kB}$ signaling}

It is well established that oxidative stress, defined as an imbalance between production and elimination of reactive oxygen species (ROS), can cause chronic inflammation, leading to transformation of a normal cell to a tumor cell. The key mediators in the inflammatory pathways modulate expression and/or activity of various transcription factors, including NF- $\kappa$ B, STAT3, and Nrf2. Therefore, to elucidate the molecular mechanisms underlying the lycopene-induced inhibition of the pathogenesis of ovarian cancer, we first examined the effect of lycopene on the NF- $\kappa \mathrm{B}$ signaling pathway. Representative Western blots are shown in Figure 3A. Quantitative analysis of protein samples extracted from the ovarian tumors in the control and lycopenefed hens showed that lycopene significantly reduced the expression level of NF- $\kappa \mathrm{B}$, suggesting that NF- $\mathrm{\kappa B}$ signaling may be a prime target for the anti-tumor effects of lycopene on ovarian cancer. As illustrated in Figure 3B, the inhibitory effect of lycopene on NF- $\mathrm{KB}$ is dose-dependent; there is a reduction of $38 \%$ and 64\% in NF-кB levels in hens treated with $200 \mathrm{mg} / \mathrm{kg}$ and $400 \mathrm{mg} / \mathrm{kg}$ of lycopene, respectively $(P<0.001)$.

\section{Lycopene decreases the expression of STAT3 by inducing the expression of protein inhibitor of activated STAT3 in the ovary of laying hen}

To further characterize the molecular mechanisms involved in the lycopene-induced changes in the ovarian carcinogenesis, we determined the effects of lycopene on the expression of STAT3, another key pro-inflammatory transcription factor activated in response to a variety of growth factors and cytokines. ${ }^{50}$ Mutations resulting in constitutively activated STAT3 have been reported to promote tumorigenesis through deregulation of cell cycle and apoptosis in ovarian cells. ${ }^{51}$ Our results demonstrated that lycopene significantly downregulates the expression of STAT3 in the ovary (Fig. 3C). We observed a reduction of $48 \%$ and $68 \%(P<$ 0.05 ) at protein levels of STAT3 in hens fed $200 \mathrm{mg} / \mathrm{kg}$ and 400 $\mathrm{mg} / \mathrm{kg}$ of lycopene, respectively. In addition, we analyzed the expression levels of the protein inhibitor of activated STAT3 (PIAS3), an upstream modulator of STAT3 that attenuates the transcriptional activity of STAT3 by inhibiting its DNA binding. ${ }^{52}$ Western blot analysis showed that lycopene significantly and dose-dependently upregulated the expression of PIAS3 in ovarian cells of laying hens (Fig. 3D). Taken together, these results suggest that overexpression of PIAS3 by lycopene contributes to suppression of tumor growth by inhibiting the function of constitutively active STAT3 in ovarian cancer cells.

Table 3. Effects of lycopene on serum MDA and lycopene levels in laying hens

\begin{tabular}{|c|c|c|c|c|}
\hline \multirow{2}{*}{ Item } & \multicolumn{3}{|c|}{ Lycopene dose $(\mathrm{mg} / \mathrm{kg}$ of diet) } & \multirow{2}{*}{$P$-value } \\
\hline & 0 & 200 & 400 & \\
\hline MDA (nmol/mL) & $2.26 \pm 0.51^{\mathrm{a}}$ & $1.65 \pm 0.39^{b}$ & $0.90 \pm 0.27^{c}$ & $<0.001$ \\
\hline Lycopene $(\mathrm{nmol} / \mathrm{mL})$ & $\mathrm{ND}^{c}$ & $6.29 \pm 1.62^{\mathrm{b}}$ & $13.75 \pm 2.13^{\mathrm{a}}$ & $<0.001$ \\
\hline
\end{tabular}

Values are presented as mean \pm SE from a 450-day animal experimentation. MDA, malondialdehyde; ND, not done. ${ }^{a-c}$ Means in the same line without a common superscript differ significantly $(P<0.05)$. 
A
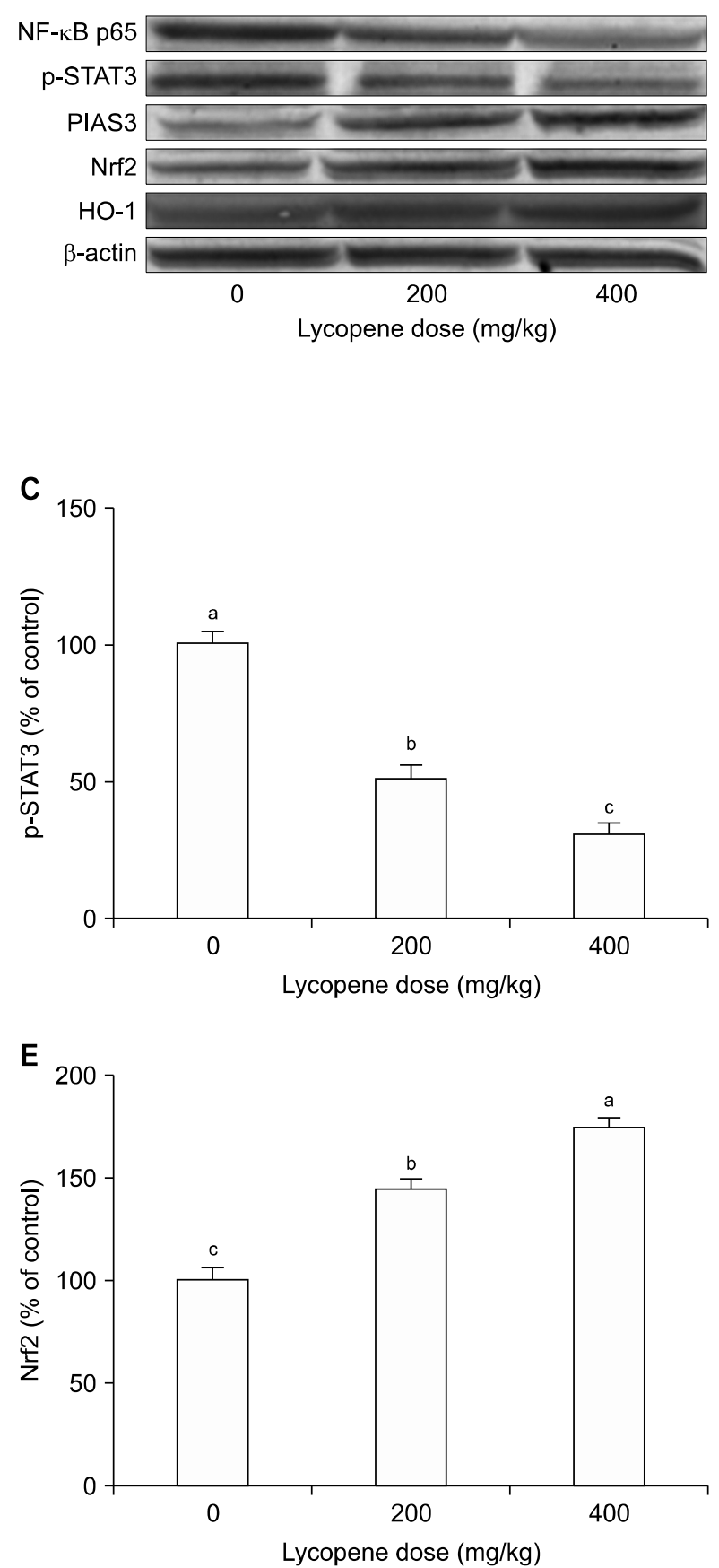

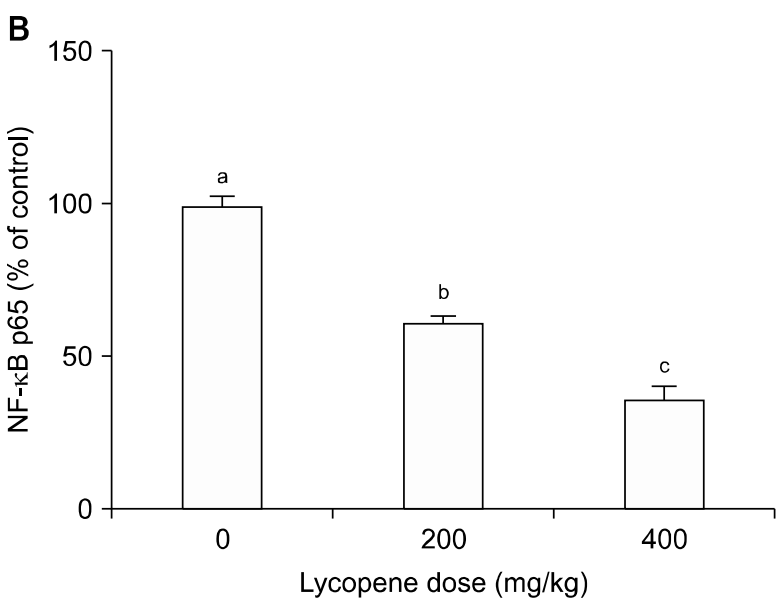

D
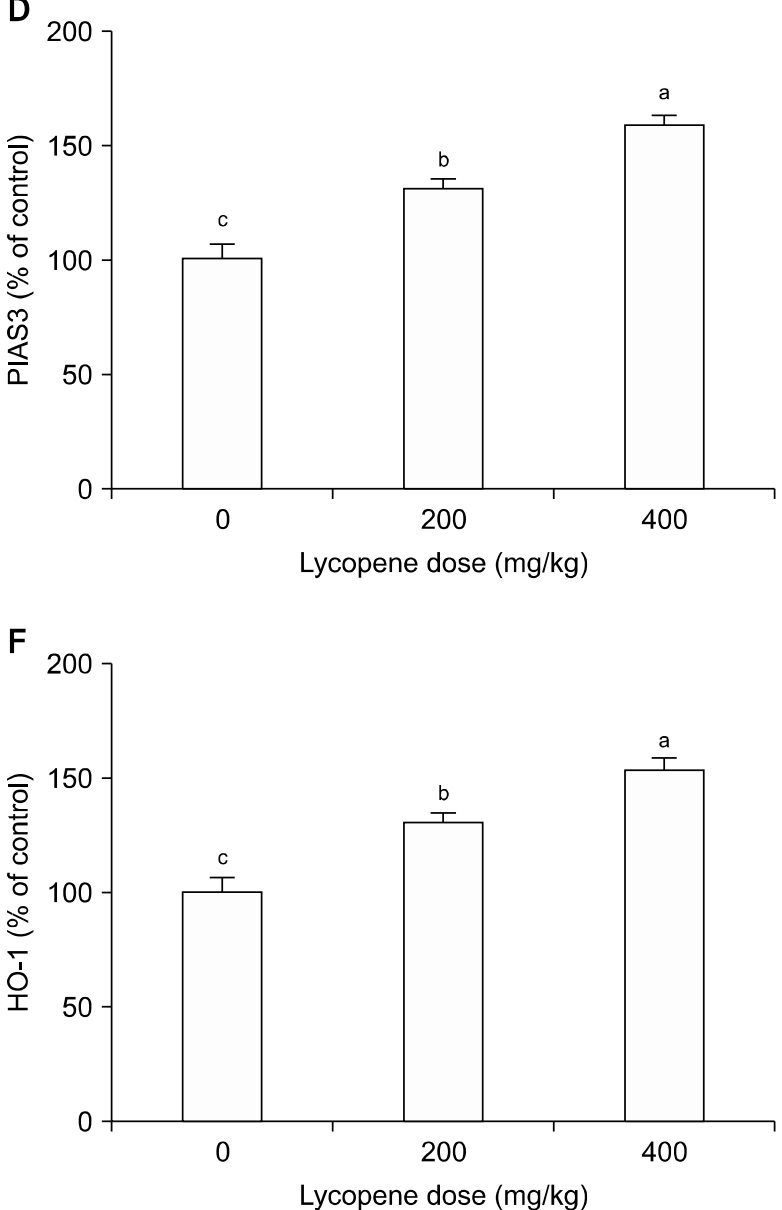

Figure 3. Representative (A) Western blots and quantitative analysis of effects of lycopene on expression levels of (B) NF- $\kappa B$, (C) STAT3, (D) protein inhibitor of activated STAT3 (PIAS3), (E) nuclear factor erythroid 2-related factor 2 (Nrf2), and (F) heme oxygenase 1 (HO-1) in hen ovarian tissue. $\beta$-Actin was used as a normalization control. Blots were repeated at least three times. Values are means \pm SE. Data are percent of the control values. Different superscript on top of each bar (a-c) indicates group mean differences $(P<0.05)$. 


\section{Lycopene enhances the expression of nuclear factor erythroid 2-related factor 2 and heme oxygenase 1 in the ovary of laying hen}

A major mechanism in the cellular defense against oxidative stress is the activation of the transcription factor Nrf2, the master regulator of antioxidant and anti-inflammatory responses. ${ }^{53}$ Therefore, enhancing the Nrf2 activity is a key approach to prevention of cancer and other diseases in which oxidative stress contributes to the pathogenesis. To investigate whether lycopene exerts antioxidant effects on ovarian cancer, we assayed the expression levels of Nrf2 and its downstream target HO-1 enzyme in tumors from control and treatment groups by Western blotting. As illustrated in Figure 3E and 3F, lycopene intervention significantly and dose-dependently increased the expression levels of Nrf2 and HO-1 in hen ovarian tumors. We observed an increase of $44 \%$ and $74 \%$ in Nrf2 levels $(P<0.01$ and $P<0.001)$, and an increase of $30 \%$ and $53 \%$ in HO-1 levels ( $P<0.05$ and $P<$ $0.001)$ in hens fed $200 \mathrm{mg} / \mathrm{kg}$ and $400 \mathrm{mg} / \mathrm{kg}$ of lycopene, respectively. Our findings provide the molecular basis of antioxidant activity of lycopene in the context of its chemoprevention of ovarian cancer.

\section{DISCUSSION}

In recent years, there has been considerable interest in the potential role of lycopene in the chemoprevention of ovarian cancer. However, only a limited number of studies have examined the relationship between dietary intake of lycopene and ovarian cancer risk, and the results have been inconsistent. A population-based study conducted by Cramer et al..$^{15}$ showed a significant inverse association between tomato sauce intake and ovarian cancer risk in premenopausal women. ${ }^{54}$ Kiani et al. ${ }^{13}$ also reported that fruit- and vegetable-rich diet and especially tomatoes were associated with a reduced ovarian cancer risk. In a case-control study, Tang et al. ${ }^{11}$ demonstrated that with the exception of lycopene, significant reductions in risk of ovarian cancer were associated with the intake of a variety of fruits and vegetables. But the amount of lycopene intake was very low in this study compared with those in other studies. Despite these favorable results, other epidemiological studies reported that intake of lycopene or other carotenoids showed no association with ovarian cancer risk. ${ }^{16.55-59} \mathrm{In}$ addition, a pooled analysis of 10 cohort studies demonstrated that intake of major carotenoids was not associated with the risk of ovarian cancer. ${ }^{12}$ Helzlsouer et al. ${ }^{60}$ reported no association between serum lycopene levels and ovarian cancer risk whereas Jeong et al. ${ }^{61}$ observed a significant inverse association between plasma levels of lycopene and ovarian cancer risk.

To the best of our knowledge, the present study is the first investigation of the preventive effects of lycopene on spontaneous ovarian cancer formation using the laying hen model. Our findings demonstrated that lycopene reduced the incidence and the size of ovarian tumors in laying hens, possibly due to its antioxidant and anti-inflammatory activities. Previous studies have shown that the laying hen provides a biologically relevant preclinical model to characterize the molecular mechanisms underlying pathogenesis of human ovarian cancer as well as to test the effects of agents on prevention of the disease. In 1987 , Fredrickson ${ }^{49}$ reported that $32 \%$ and $8 \%$ of white leghorn hens developed spontaneous ovarian and oviductal adenocarcinomas, respectively. In addition, granulosa and sertoli cells tumors were observed in $8 \%$ of the hens. As in women, high ovulation rate has been correlated with the risk of ovarian cancer in laying hens. Moreover, there is an age-related increase in the incidence of ovarian cancer in hens as egg production decreases. Molecular characterization of chicken ovarian cancer cells has shown high expression of several biomarkers, including EGFR, tumorassociated glycoprotein 72 , PCNA, TGF- $\alpha$, and CA125, as in human ovarian tumors. ${ }^{42,43}$ In addition, Barua et al.$^{46}$ demonstrated that similar to humans, four histological subtypes, including serous, endometrioid, mucinous, clear cell carcinomas, are observed in chicken ovarian tumors.

It is well documented that ovarian carcinogenesis has been associated with chronic inflammation which is induced by oxidative stress. ${ }^{62}$ In eukaryotic cells, ROS are products of normal metabolic reactions and are required for stimulation of signal transduction pathways in response to cellular changes. ${ }^{63}$ However, when the equilibrium between ROS and endogenous antioxidants is perturbed, oxidative stress is generated, damaging important biomolecules, including DNA, RNA, lipids, and proteins, leading to neoplastic transformation. ${ }^{64}$ Oxidative stress modulates the expression of a variety of transcription factors, including NF- $\mathrm{KB}$, STAT3, hypoxia-inducible factor 1- $\alpha$, AP-1, p53, PPAR- $\gamma, \beta-$ catenin/Wnt, and Nrf2, which mediate immediate cellular stress responses. Therefore, targeting ROS-induced signaling pathways by antioxidant agents offers an effective strategy for cancer prevention.

In the ovarian surface epithelium, the injury and tissue remodeling caused by ovulation trigger the inflammatory cascade. It has been reported that the inflammatory events caused by repetitive ovulation over the lifetime increase the risk of DNA 
damage during the repair process, predisposing the ovarian surface epithelial cells to neoplastic transformation by the accumulation of genetic mutations. ${ }^{65}$ The evidence that oral contraceptive use, parity and breast-feeding reduce ovarian cancer risk supports the role of inflammation in ovarian carcinogenesis. ${ }^{66}$

Lycopene is the most effective singlet oxygen quencher among 600 naturally occurring carotenoids, supporting its strong antioxidant activity. ${ }^{67}$ Several studies demonstrated that lycopene modulates ROS levels, leading to inhibition of ROS-induced cell damage. ${ }^{68}$ Excessive ROS has been shown to induce lipid peroxidation of polyunsaturated fatty acids. ${ }^{69} \mathrm{MDA}$, which is one of the end products of lipid peroxidation, is a commonly used biomarker for oxidative stress. ${ }^{70}$ We have previously reported that lycopene supplementation reduced the incidence of spontaneous leiomyomas of the oviduct in Japanese quail. ${ }^{71}$ Additionally, serum MDA levels were significantly reduced in lycopene fed birds, consistent with data previously published by others. ${ }^{72}$ Our present study showed that lycopene intervention resulted in a significant and dose-dependent reduction of serum MDA levels in laying hens, suggesting that lycopene exerts its chemopreventive effects via oxidative stress-induced signaling pathways. Based on this finding, we hypothesized that lycopene could ameliorate oxidative stress-induced inflammation in the ovary of laying hens through regulation of NF-KB, STAT3, and Nrf2 pathways.

NF-KB is a key transcription factor that acts as a molecular link between inflammation and cancer. The NF- $\mathrm{KB}$ pathway is activated by ROS in response to inflammatory cytokines and proteins, and plays a critical role in cell proliferation, survival, adhesion, differentiation and cell growth, inducing tumor initiation and progression. ${ }^{73.74}$ Our data showed that lycopene supplementation significantly reduced the expression of NF- $\mathrm{KB}$ in the ovary of laying hen, supporting the hypothesis that lycopene mediates its chemopreventive effects on the ovarian carcinogenesis through inhibition of NF- $\mathrm{KB}$ signaling.

Molecular studies have shown that the JAK2/STAT3 pathway plays a regulatory role in oxidative stress as well as inflammation. ${ }^{75}$ JAK2/STAT3 signaling modulates cellular activities, including proliferation, migration, differentiation and death. ${ }^{76}$ In normal cells, the JAK2/STAT3 pathway is transiently activated primarily by growth factors and cytokines as well as toll-like receptors, microRNAs, and G protein-coupled receptors. ${ }^{77-80}$ However, in cancer cells, including breast, ovarian and prostate tumors, the JAK2/STAT3 pathway has been shown to be constitutively active. ${ }^{51}$ Therefore, it is essential to develop effective approaches to inhibit the JAK2/STAT3 signaling pathway for prevention and treatment of cancer. Our findings showed that lycopene significantly reduced the STAT3 expression while enhancing the expression of its upstream regulator PIAS3, suggesting that inhibition of STAT3 via overexpression of PIAS3 results in a protective effect against ovarian carcinogenesis.

The Nrf2 pathway plays a crucial role in cellular defense by sensing the level of oxidative stress induced by ROS, and regulating the expression of antioxidant proteins and detoxification enzymes, maintaining cellular redox homeostasis. ${ }^{81}$ In addition to its primary role in cytoprotection, the transcription factor Nrf2 is also involved in diverse cellular processes, including differentiation, proliferation, apoptosis, inflammation, and lipid synthesis. ${ }^{82}$ In the present study, we demonstrated that lycopene intervention significantly increased the expression levels of Nrf2 and its downstream target HO-1 in hen ovarian cancer cells, providing further support for the involvement of antioxidant activity of lycopene in chemoprevention of ovarian cancer.

In conclusion, our findings indicate that dietary intake of lycopene reduces the incidence and the size of spontaneous ovarian tumors in the laying hen model. We have also observed that lycopene exerts potent antioxidant and anti-inflammatory activities in ovarian cells by modulating diverse signaling pathways, including NF-KB, STAT3, and Nrf2, contributing to prevention of ovarian cancer. Taken together, these data provide further support and mechanistic insights into the chemopreventive effects of lycopene on ovarian cancer in a biologically relevant in vivo model. Our results warrant further pre-clinical and clinical studies to assess the preventive effects of lycopene, and potentially improve the clinical outcomes and overall survival rates of patients with ovarian cancer.

\section{CONFLICTS OF INTEREST}

No potential conflicts of interest were disclosed.

\section{REFERENCES}

1. Ferlay J, Soerjomataram I, Dikshit R, Eser S, Mathers C, Rebelo M, et al. Cancer incidence and mortality worldwide: sources, methods and major patterns in GLOBOCAN 2012. Int J Cancer 2015; 136:E359-86.

2. Siegel RL, Miller KD, Jemal A. Cancer statistics, 2017. CA Cancer J Clin 2017;67:7-30.

3. Hanna L, Adams M. Prevention of ovarian cancer. Best Pract Res Clin Obstet Gynaecol 2006;20:339-62.

4. Lu KH, Skates S, Hernandez MA, Bedi D, Bevers T, Leeds L, et al. A 2-stage ovarian cancer screening strategy using the Risk of Ovarian Cancer Algorithm (ROCA) identifies early-stage incident- 
cancers and demonstrates high positive predictive value. Cancer 2013;119:3454-61.

5. Cohen JG, White M, Cruz A, Farias-Eisner R. In 2014, can we do better than CA125 in the early detection of ovarian cancer? World J Biol Chem 2014:5:286-300.

6. Brain KE, Smits S, Simon AE, Forbes LJ, Roberts C, Robbé IJ, et al. Ovarian cancer symptom awareness and anticipated delayed presentation in a population sample. BMC Cancer 2014;14:171.

7. Goodman MT, Correa CN, Tung KH, Roffers SD, Cheng Wu X, Young JL Jr, et al. Stage at diagnosis of ovarian cancer in the United States, 1992-1997. Cancer 2003:97(10 Suppl):2648-59.

8. Bast RC Jr, Urban N, Shridhar V, Smith D, Zhang Z, Skates S, et al. Early detection of ovarian cancer: promise and reality. Cancer Treat Res 2002;107:61-97.

9. Stewart BW, Kleihues P. World cancer report. Lyon, IARC Press, 2003.

10. Falk RT, Fears TR, Xu X, Hoover RN, Pike MC, Wu AH, et al. Urinary estrogen metabolites and their ratio among Asian American women. Cancer Epidemiol Biomarkers Prev 2005;14: 221-6.

11. Tang L, Lee AH, Su D, Binns CW. Fruit and vegetable consumption associated with reduced risk of epithelial ovarian cancer in southern Chinese women. Gynecol Oncol 2014;132:241-7.

12. Koushik A, Hunter DJ, Spiegelman D, Anderson KE, Buring JE, Freudenheim JL, et al. Intake of the major carotenoids and the risk of epithelial ovarian cancer in a pooled analysis of 10 cohort studies. Int J Cancer 2006;119:2148-54.

13. Kiani F, Knutsen S, Singh P, Ursin G, Fraser G. Dietary risk factors for ovarian cancer: the Adventist Health Study (United States). Cancer Causes Control 2006;17:137-46.

14. Tung KH, Wilkens LR, Wu AH, McDuffie K, Hankin JH, Nomura $\mathrm{AM}$, et al. Association of dietary vitamin A, carotenoids, and other antioxidants with the risk of ovarian cancer. Cancer Epidemiol Biomarkers Prev 2005;14:669-76.

15. Cramer DW, Kuper H, Harlow BL, Titus-Ernstoff L. Carotenoids, antioxidants and ovarian cancer risk in pre- and postmenopausal women. Int J Cancer 2001;94:128-34.

16. McCann SE, Moysich KB, Mettlin C. Intakes of selected nutrients and food groups and risk of ovarian cancer. Nutr Cancer 2001; 39:19-28.

17. Rao AV, Rao LG. Carotenoids and human health. Pharmacol Res 2007; 55:207-16.

18. Rao AV, Ray MR, Rao LG. Lycopene. Adv Food Nutr Res 2006; 51:99-164.

19. Krinsky NI. The antioxidant and biological properties of the carotenoids. Ann N Y Acad Sci 1998;854:443-7.

20. Liu C, Lian F, Smith DE, Russell RM, Wang XD. Lycopene supplementation inhibits lung squamous metaplasia and induces apoptosis via up-regulating insulin-like growth factor-binding protein 3 in cigarette smoke-exposed ferrets. Cancer Res 2003;63:3138-44.

21. Chen $\mathrm{CP}$, Hung $\mathrm{CF}$, Lee $\mathrm{SC}$, Lo HM, Wu PH, Wu WB. Lycopene binding compromised PDGF-AA/-AB signaling and migration in smooth muscle cells and fibroblasts: prediction of the possible lycopene binding site within PDGF. Naunyn Schmiedebergs Arch Pharmacol 2010;381:401-14.

22. Chen ML, Lin YH, Yang CM, Hu ML. Lycopene inhibits angiogenesis both in vitro and in vivo by inhibiting MMP-2/uPA system through VEGFR2-mediated PI3K-Akt and ERK/p38 signaling pathways. Mol Nutr Food Res 2012;56:889-99.
23. Nahum A, Hirsch K, Danilenko M, Watts CK, Prall OW, Levy J, et al. Lycopene inhibition of cell cycle progression in breast and endometrial cancer cells is associated with reduction in cyclin D levels and retention of p27(Kip1) in the cyclin E-cdk2 complexes. Oncogene 2001;20:3428-36.

24. Ford NA, Elsen AC, Zuniga K, Lindshield BL, Erdman JW Jr. Lycopene and apo-12'-lycopenal reduce cell proliferation and alter cell cycle progression in human prostate cancer cells. Nutr Cancer 2011;63:256-63.

25. Hantz HL, Young LF, Martin KR. Physiologically attainable concentrations of lycopene induce mitochondrial apoptosis in LNCaP human prostate cancer cells. Exp Biol Med (Maywood) 2005;230: 171-9.

26. Palozza P, Serini S, Boninsegna A, Bellovino D, Lucarini M, Monastra G, et al. The growth-inhibitory effects of tomatoes digested in vitro in colon adenocarcinoma cells occur through down regulation of cyclin D1, Bcl-2 and Bcl-xL. Br J Nutr 2007;98: 789-95.

27. Lin MC, Wang FY, Kuo YH, Tang FY. Cancer chemopreventive effects of lycopene: suppression of MMP-7 expression and cell invasion in human colon cancer cells. J Agric Food Chem 2011; 59:11304-18.

28. Hwang ES, Lee HJ. Inhibitory effects of lycopene on the adhesion, invasion, and migration of SK-Hep1 human hepatoma cells. Exp Biol Med (Maywood) 2006;231:322-7.

29. Livny O, Kaplan I, Reifen R, Polak-Charcon S, Madar Z, Schwartz $B$. Lycopene inhibits proliferation and enhances gap-junction communication of KB-1 human oral tumor cells. J Nutr 2002;132: 3754-9.

30. Amir H, Karas M, Giat J, Danilenko M, Levy R, Yermiahu T, et al. Lycopene and 1,25-dihydroxyvitamin D3 cooperate in the inhibition of cell cycle progression and induction of differentiation in HL-60 leukemic cells. Nutr Cancer 1999;33:105-12.

31. Tang FY, Pai MH, Kuo YH, Wang XD. Concomitant consumption of lycopene and fish oil inhibits tumor growth and progression in a mouse xenograft model of colon cancer. Mol Nutr Food Res 2012;56:1520-31.

32. Al-Malki AL, Moselhy SS, Refai MY. Synergistic effect of lycopene and tocopherol against oxidative stress and mammary tumorigenesis induced by 7,12-dimethyl[a]benzanthracene in female rats. Toxicol Ind Health 2012;28:542-8.

33. Sahin K, Tuzcu M, Sahin N, Akdemir F, Ozercan I, Bayraktar S, et al. Inhibitory effects of combination of lycopene and genistein on 7,12- dimethyl benz(a)anthracene-induced breast cancer in rats. Nutr Cancer 2011;63:1279-86.

34. Tang Y, Parmakhtiar B, Simoneau AR, Xie J, Fruehauf J, Lilly M, et al. Lycopene enhances docetaxel's effect in castration-resistant prostate cancer associated with insulin-like growth factor I receptor levels. Neoplasia 2011;13:108-19.

35. Dogukan A, Tuzcu M, Agca CA, Gencoglu H, Sahin N, Onderci M, et al. A tomato lycopene complex protects the kidney from cisplatin-induced injury via affecting oxidative stress as well as Bax, Bcl-2, and HSPs expression. Nutr Cancer 2011;63:427-34.

36. Preet R, Mohapatra P, Das D, Satapathy SR, Choudhuri T, Wyatt $\mathrm{MD}$, et al. Lycopene synergistically enhances quinacrine action to inhibit Wnt-TCF signaling in breast cancer cells through APC. Carcinogenesis 2013;34:277-86.

37. Andic F, Garipagaoglu M, Yurdakonar E, Tuncel N, Kucuk O. Lycopene in the prevention of gastrointestinal toxicity of 
radiotherapy. Nutr Cancer 2009:61:784-8.

38. Srinivasan M, Devipriya N, Kalpana KB, Menon VP. Lycopene: an antioxidant and radioprotector against gamma-radiation-induced cellular damages in cultured human lymphocytes. Toxicology 2009:262:43-9.

39. Damjanov I. Ovarian tumours in laboratory and domestic animals. Curr Top Pathol 1989;78:1-10.

40. Murdoch WJ, Van Kirk EA, Alexander BM. DNA damages in ovarian surface epithelial cells of ovulatory hens. Exp Biol Med (Maywood) 2005:230:429-33.

41. Treviño LS, Buckles EL, Johnson PA. Oral contraceptives decrease the prevalence of ovarian cancer in the hen. Cancer Prev Res (Phila) 2012;5:343-9.

42. Jackson E, Anderson K, Ashwell C, Petitte J, Mozdziak PE. CA125 expression in spontaneous ovarian adenocarcinomas from laying hens. Gynecol Oncol 2007;104:192-8.

43. Rodríguez-Burford C, Barnes MN, Berry W, Partridge EE, Grizzle WE. Immunohistochemical expression of molecular markers in an avian model: a potential model for preclinical evaluation of agents for ovarian cancer chemoprevention. Gynecol Oncol 2001;81:373-9.

44. Zhuge Y, Lagman JA, Ansenberger K, Mahon CJ, Daikoku T, Dey SK, et al. CYP1B1 expression in ovarian cancer in the laying hen Gallusdomesticus. Gynecol Oncol 2009;112:171-8.

45. Urick ME, Giles JR, Johnson PA. VEGF expression and the effect of NSAIDs on ascites cell proliferation in the hen model of ovarian cancer. Gynecol Oncol 2008;110:418-24.

46. Barua A, Bitterman P, Abramowicz JS, Dirks AL, Bahr JM, Hales $\mathrm{DB}$, et al. Histopathology of ovarian tumors in laying hens: a preclinical model of human ovarian cancer. Int J Gynecol Cancer 2009;19:531-9.

47. Sahin K, Yazlak H, Orhan C, Tuzcu M, Akdemir F, Sahin N. The effect of lycopene on antioxidant status in rainbow trout (Oncorhynchus mykiss) reared under high stocking density. Aquaculture 2014;418-419:132-8.

48. Sahin K, Orhan C, Yazlak H, Tuzcu M, Sahin N. Lycopene improves activation of antioxidant system and Nrf2/HO-1 pathway of muscle in rainbow trout (Oncorhynchus mykiss) with different stocking densities. Aquaculture 2014:430:133-8.

49. Fredrickson TN. Ovarian tumors of the hen. Environ Health Perspect 1987:73:35-51

50. Stark GR, Kerr IM, Williams BR, Silverman RH, Schreiber RD. How cells respond to interferons. Annu Rev Biochem 1998;67: 227-64.

51. Rosen DG, Mercado-Uribe I, Yang G, Bast RC Jr, Amin HM, Lai R, et al. The role of constitutively active signal transducer and activator of transcription 3 in ovarian tumorigenesis and prognosis. Cancer 2006:107:2730-40.

52. Chung CD, Liao J, Liu B, Rao X, Jay P, Berta P, et al. Specific inhibition of Stat3 signal transduction by PIAS3. Science 1997;278: 1803-5.

53. Ramos-Gomez M, Kwak MK, Dolan PM, Itoh K, Yamamoto M, Talalay P, et al. Sensitivity to carcinogenesis is increased and chemoprotective efficacy of enzyme inducers is lost in nrf2 transcription factor-deficient mice. Proc Natl Acad Sci U S A 2001; 98:3410-5.

54. Li X, Xu J. Meta-analysis of the association between dietary lycopene intake and ovarian cancer risk in postmenopausal women. Sci Rep 2014:4:4885.
55. Thomson CA, Neuhouser ML, Shikany JM, Caan BJ, Monk BJ, Mossavar-Rahmani Y, et al. The role of antioxidants and vitamin A in ovarian cancer: results from the Women's Health Initiative. Nutr Cancer 2008;60:710-9.

56. Fairfield KM, Hankinson SE, Rosner BA, Hunter DJ, Colditz GA, Willett WC. Risk of ovarian carcinoma and consumption of vitamins $\mathrm{A}, \mathrm{C}$, and $\mathrm{E}$ and specific carotenoids: a prospective analysis. Cancer 2001;92:2318-26.

57. Silvera SA, Jain M, Howe GR, Miller AB, Rohan TE. Carotenoid, vitamin $\mathrm{A}$, vitamin $\mathrm{C}$, and vitamin $\mathrm{E}$ intake and risk of ovarian cancer: a prospective cohort study. Cancer Epidemiol Biomarkers Prev 2006;15:395-7.

58. Zhang M, Holman CD, Binns CW. Intake of specific carotenoids and the risk of epithelial ovarian cancer. Br J Nutr 2007;98:187-93.

59. Gifkins D, Olson SH, Paddock L, King M, Demissie K, Lu SE, et al. Total and individual antioxidant intake and risk of epithelial ovarian cancer. BMC Cancer 2012;12:211.

60. Helzlsouer KJ, Alberg AJ, Norkus EP, Morris JS, Hoffman SC, Comstock GW. Prospective study of serum micronutrients and ovarian cancer. J Natl Cancer Inst 1996;88:32-7.

61. Jeong NH, Song ES, Lee JM, Lee KB, Kim MK, Cheon JE, et al. Plasma carotenoids, retinol and tocopherol levels and the risk of ovarian cancer. Acta Obstet Gynecol Scand 2009;88:457-62.

62. Cramer DW, Welch WR. Determinants of ovarian cancer risk. II. Inferences regarding pathogenesis. J Natl Cancer Inst 1983;71: $717-21$.

63. Jabs T. Reactive oxygen intermediates as mediators of programmed cell death in plants and animals. Biochem Pharmacol 1999:57:231-45.

64. Fang J, Seki T, Maeda H. Therapeutic strategies by modulating oxygen stress in cancer and inflammation. Adv Drug Deliv Rev 2009;61:290-302.

65. Fleming JS, Beaugié CR, Haviv I, Chenevix-Trench G, Tan OL. Incessant ovulation, inflammation and epithelial ovarian carcinogenesis: revisiting old hypotheses. Mol Cell Endocrinol 2006;247:4-21.

66. Gwinn ML, Lee NC, Rhodes PH, Layde PM, Rubin GL. Pregnancy, breast feeding, and oral contraceptives and the risk of epithelial ovarian cancer. J Clin Epidemiol 1990;43:559-68.

67. Di Mascio P, Kaiser S, Sies H. Lycopene as the most efficient biological carotenoid singlet oxygen quencher. Arch Biochem Biophys 1989:274:532-8.

68. Palozza P, Parrone N, Catalano A, Simone R. Tomato lycopene and inflammatory cascade: basic interactions and clinical implications. Curr Med Chem 2010;17:2547-63.

69. Dix TA, Aikens J. Mechanisms and biological relevance of lipid peroxidation initiation. Chem Res Toxicol 1993;6:2-18.

70. Esterbauer H, Schaur RJ, Zollner H. Chemistry and biochemistry of 4-hydroxynonenal, malonaldehyde and related aldehydes. Free Radic Biol Med 1991;11:81-128.

71. Sahin K, Ozercan R, Onderci M, Sahin N, Gursu MF, Khachik F, et al. Lycopene supplementation prevents the development of spontaneous smooth muscle tumors of the oviduct in Japanese quail. Nutr Cancer 2004:50:181-9.

72. Leal M, Shimada A, Ruíz F, González de Mejía E. Effect of lycopene on lipid peroxidation and glutathione-dependent enzymes induced by T-2 toxin in vivo. Toxicol Lett 1999;109:1-10.

73. Karin M. Nuclear factor-kappaB in cancer development and progression. Nature 2006;441:431-6. 
74. Nishio H, Yaguchi T, Sugiyama J, Sumimoto H, Umezawa K, Iwata $\mathrm{T}$, et al. Immunosuppression through constitutively activated NF- $\mathrm{KB}$ signalling in human ovarian cancer and its reversal by an NF- $\kappa B$ inhibitor. Br J Cancer 2014;110:2965-74.

75. Li R, Cai L, Ren DY, Xie XF, Hu CM, Li J. Therapeutic effect of 7 , 3'-dimethoxy hesperetin on adjuvant arthritis in rats through inhibiting JAK2-STAT3 signal pathway. Int Immunopharmacol 2012; 14:157-63

76. Duan W, Yang Y, Yan J, Yu S, Liu J, Zhou J, et al. The effects of curcumin post-treatment against myocardial ischemia and reperfusion by activation of the JAK2/STAT3 signaling pathway. Basic Res Cardiol 2012;107:263.

77. Wang X, Crowe PJ, Goldstein D, Yang JL. STAT3 inhibition, a novel approach to enhancing targeted therapy in human cancers (review). Int J Oncol 2012;41:1181-91.

78. Kortylewski M, Kujawski M, Herrmann A, Yang C, Wang L, Liu Y, et al. Toll-like receptor 9 activation of signal transducer and activator of transcription 3 constrains its agonist-based immuno- therapy. Cancer Res 2009;69:2497-505.

79. Sugimura $\mathrm{K}$, Miyata H, Tanaka K, Hamano R, Takahashi $T$, Kurokawa $\mathrm{Y}$, et al. Let-7 expression is a significant determinant of response to chemotherapy through the regulation of IL-6/ STAT3 pathway in esophageal squamous cell carcinoma. Clin Cancer Res 2012;18:5144-53.

80. Xin H, Lu R, Lee H, Zhang W, Zhang C, Deng J, et al. G-protein-coupled receptor agonist BV8/prokineticin-2 and STAT3 protein form a feed-forward loop in both normal and malignant myeloid cells. J Biol Chem 2013;288:13842-9.

81. Miao W, Hu L, Scrivens PJ, Batist G. Transcriptional regulation of NF-E2 p45-related factor (NRF2) expression by the aryl hydrocarbon receptor-xenobiotic response element signaling pathway: direct cross-talk between phase I and II drug-metabolizing enzymes. J Biol Chem 2005;280:20340-8.

82. Li Y, Paonessa JD, Zhang Y. Mechanism of chemical activation of Nrf2. PLoS One 2012;7:e35122. 